\title{
Preparation and characterization of rubbery epoxy/multiwall carbon nanotubes composites using amino acid salt assisted dispersion technique
}

\author{
S. B. Jagtap, D. Ratna* \\ Naval Materials Research Laboratory, Shil-Badlapur Road, Anand nagar P.O., District Thane, Maharashtra 421506 , \\ 421506 Ambernath, India
}

Received 8 October 2012; accepted in revised form 6 December 2012

\begin{abstract}
Epoxy/multiwall carbon nanotubes (MWCNT) composites were prepared using sodium salt of 6-aminohexanoic acid (SAHA) modified MWCNT and its effect properties of related composites were investigated. The composite prepared using a polar solvent, tetrahydrofuran exhibits better mechanical properties compared to those prepared using less polar solvent and without using solvent. The tensile properties and dynamic storage modulus was found to be increased as a result of modification of MWCNT with SAHA. This improvement in the tensile properties and dynamic mechanical properties of epoxy/MWCNT composite is a combined effect of cation- $\pi$ interaction and chemical bonding. Fourier transform infrared spectroscopy (FTIR) and Raman spectroscopy were used to explain cation- $\pi$ interaction between SAHA with MWCNT and chemical bonding of SAHA with epoxy resin. The effect of modification of MWCNT on morphology of a nanocomposite was confirmed by using scanning electron microscopy (SEM) and transmission electron microscopy (TEM). The present approach does not disturb the $\pi$ electron clouds of MWCNT as opposed to chemical functionalization strategy.
\end{abstract}

Keywords: nanocomposites, mechanical properties, carbon nanotubes, epoxy resin

\section{Introduction}

Carbon nanotubes (CNTs)-based polymer composites have many potential applications due to their extraordinary properties [1-9]. CNTs offer significant improvements in the various properties of polymers for wide variety of applications. Initial academic research on polymer/CNT nanocomposites has been focused on single wall carbon nanotubes (SWCNT) because of their simpler structure. However, the extremely high cost of SWCNT considerably restricts the commercialization of CNT-based composites. Nowadays, the production of multiwall carbon nanotubes (MWCNT) has already been scaled up by the industries and therefore the research interest has been diverted towards the technological pro- liferation of MWCNT-based systems [10-12]. However, the strong tendency of MWCNT to form agglomerates (due to Van der Waals forces) makes the nanotubes incompatible with the polymer matrix. Hence, homogeneous dispersion of MWCNT still remains as a great challenge. Several strategies such as high shear mixing, ultrasonication, surface oxidation (covalent functionalization) and the use of surfactant have been addressed to overcome the obstacle of agglomeration [13-14]. The surface oxidation is most widely used to achieve the desired properties. However, generation of functional groups due to the surface oxidation create the structural defect to the MWCNT (which disturb the $\pi$ electron cloud) and deteriorate the intrinsic properties of MWCNT.

\footnotetext{
${ }^{*}$ Corresponding author, e-mail: ratnad29@hotmail.com (C) BME-PT
} 
Recently, 'cation- $\pi$ ' interaction by using surfactant has been realized as the best way to achieve good dispersion of MWCNT and interfacial interaction [15-18]. The cation of such modifiers interacts with the $\pi$ electron clouds of MWCNT and reduces the Van der Waals force. This method does not disturb the $\pi$ electron clouds of MWCNT. In the present paper, we described the cation- $\pi$ interaction using a sodium salt of 6-aminohexanoic acid (SAHA) as a modifier and MWCNT into the epoxy matrix. Though the modifier has been used for melt blending process by others [16], to our knowledge it has not been directly used for thermoset epoxy matrix.

Studies on epoxy/MWCNT composites are reported to date are mostly related to high $T_{\mathrm{g}}$ (glassy) epoxy systems [19-24]. In the present paper, we used rubbery epoxy matrix $\left(T_{\mathrm{g}} \sim 5^{\circ} \mathrm{C}\right)$ to study the reinforcing effect of MWCNT because the reinforcing effect in a flexible matrix is more prominent than that observed in a glassy one [25]. The rubbery epoxies are particularly important because of their use for vibration damping application [26]. However, poor mechanical properties of such flexible epoxies are a major drawback which restricts their application. That is why we used MWCNT to improve the mechanical properties of such rubbery epoxy. The modifier SAHA is designed in such way that it contains a cation $\left(\mathrm{Na}^{+}\right)$, which interacts with the $\pi$ electron clouds of MWCNT via cation- $\pi$ interaction and the free $-\mathrm{NH}_{2}$ group can form chemical bonding with the epoxy resin. In this way, the nanotubes become an integral part of cross linking through chemical bonding between SAHA and epoxy resin. This provides an effective load transfer from epoxy matrices to nanotubes for the enhancement of mechanical properties. The nanocomposites prepared by using the present method is expected to improve dispersion of MWCNT in the flexible epoxy matrix. The effect of SAHA modified MWCNT on the mechanical, dynamic mechanical properties and morphology of the epoxy matrix will be discussed in the present paper.

\section{Experimental}

\subsection{Materials}

Epoxy resin diglycidyl ether of bisphenol A (DGEBA) (LY556) was purchased from Vantico (USA). Poly(oxypropylene) diamine (Jeffamine ED900, Sigma Aldrich, USA) was added as a curing agent for epoxy. MWCNT (Baytube ${ }^{\circledR} 150 \mathrm{P}$ ) was procured from Bayer Material Science AG (Leverkusen, Germany). The MWCNTs synthesized by the chemical vapor deposition (CVD) method having purity $95 \%$ with diameter in the range of 5-20 $\mathrm{nm}$ and the length $1-10 \mu \mathrm{m}$. 6-aminohexanoic acid (purity - 98\%) and sodium hydroxide (98\%) were purchased from Merck chemical, Germany. Acetone and tetrahydrofuran were used as received and purchased from Merck chemical, Germany.

\subsection{Preparation of nanocomposites}

The SAHA modified MWCNT was prepared by mixing of 6-amino hexanoic acid, sodium hydroxide (1:1 mass ratio w/w) and MWCNT in $100 \mathrm{~mL}$ distilled water in $250 \mathrm{~mL}$ beaker. The mixture was sonicated for 20 min using a probe sonication (Bandelin Ultrasonic homogenizer, SONOPULS HD3200 , working frequency $20 \mathrm{kHz}$, Germany), keeping the beaker immersed in cold water. The water was removed by applying vacuum and the mixture was dried at $100^{\circ} \mathrm{C}$ for $24 \mathrm{~h}$. Composites with unmodified and SAHA-modified MWCNT were prepared using small amount (20 wt $\%)$ of solvent. A typical procedure for preparation of nanocomposites using solvent is described as follows. $0.125 \mathrm{~g}$ MWCNT was added into solvent and sonicated using a probe sonication for $1 \mathrm{~h}$. $25 \mathrm{~g}$ epoxy resin was added into it and the mixture was again sonicated for $20 \mathrm{~min}$, keeping the beaker immersed in cold water. The solvent was removed by applying vacuum. Then, $19 \mathrm{~g}$ of curing agent (JeffamineED 900) was added into the mixture, mixed uniformly for $15 \mathrm{~min}$, degassed for $10 \mathrm{~min}$ and allows to cure in Teflon mold at $80^{\circ} \mathrm{C}$ for $6 \mathrm{~h}$. Figure 1 illustrates the flow chart of nanocomposites preparation by using solution. The composites prepared using solvent with unmodified MWCNT and SAHA-modified MWCNT are designated as epoxy/MWCNT(0.5 wt\%) and epoxy/ MWCNT $(0.1,0.25,0.5,0.75,1,1.5$ and $2 \mathrm{wt} \%) /$ SAHA, respectively.

For comparison the epoxy composite with SAHA modified MWCNT was also made without using solvent. A typical procedure for nanocomposites prepared without using solvent is described as follows. $0.125 \mathrm{~g}$ MWCNT was added into $25 \mathrm{~g}$ epoxy resin and stirred for $2 \mathrm{~h}$ using mechanical stirrer. The mixture was sonicated for 20 min, keeping the beaker immersed in cold water. The $19 \mathrm{~g}$ of Jeffamine 900 was added into it, mixed uniformly for 


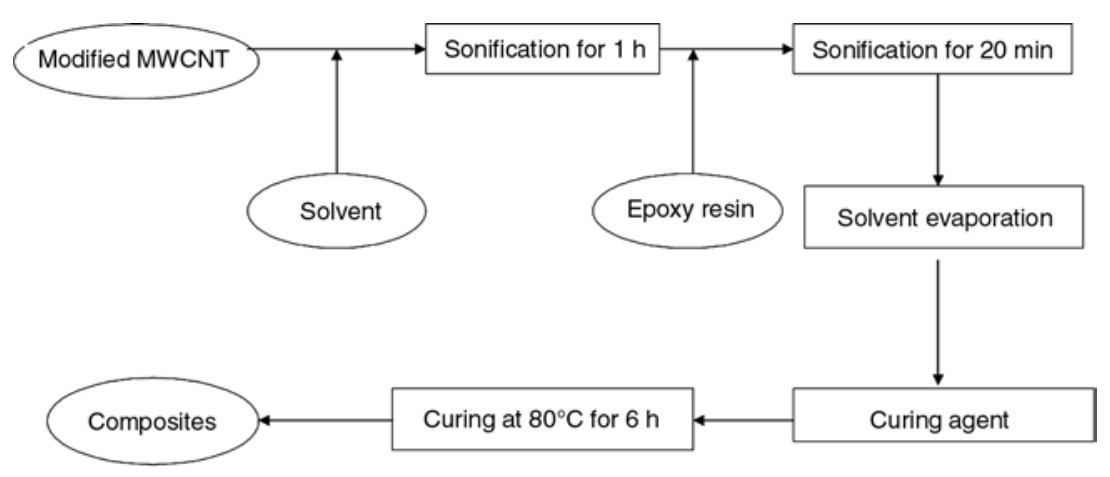

Figure 1. Flow chart of preparation of epoxy/MWCNT nanocomposites by using solvent

$15 \mathrm{~min}$, degassed for $10 \mathrm{~min}$ and allowed to cure in Teflon mold at $80^{\circ} \mathrm{C}$ for $6 \mathrm{~h}$.

\subsection{Characterization}

\subsubsection{Tensile properties}

The tensile strength, tensile modulus and \% elongation at break of neat epoxy and nanocomposites sample were measured using a (Hounsfield $50 \mathrm{KS}$ Instron, UK) Universal Testing Machine (UTM) according to ASTM D 638. The crosshead speed was $100 \mathrm{~mm} / \mathrm{min}$ and the gauge length was $50 \mathrm{~mm}$. All the tests were performed at $27 \pm 2^{\circ} \mathrm{C}$ and the results are expressed in $\mathrm{MPa}$. The quoted result is an average of the values obtained from four dumbbells.

\subsubsection{Microscopic properties}

A high resolution scanning electron microscope (FEG-SEM, Zeissa Supra 40 VP, Germany) was used to study the fractured surface morphology of epoxy/MWCNT composite samples. The composite samples were quenched in liquid nitrogen and cryogenically fractured to obtain the cross sections, which were sputter coated with carbon to avoid the charging before the SEM observation. High resolution transmission electron microscope (HRTEM) analysis of the epoxy/MWCNT composite samples was conducted on a JEOL, (JEM-2100, Japan) electron microscope at $200 \mathrm{KV}$. Ultra-thin sections of composite films were prepared with the thickness of 130-150 nm for TEM imaging using Leica ultracut microtome (Leica Mikrosysteme, GmbH, A1170, Austria) using liquid nitrogen.

\subsubsection{Spectroscopic properties}

Fourier transform infrared (FTIR) spectra of MWCNT, SAHA-modified MWCNT and their composite samples were taken with attenuated total reflection (ATR) mode by a Nicolet 510 FTIR spectrometer, Germany over a scanning range from 1000 to $2000 \mathrm{~cm}^{-1}$ with a nominal resolution of $2 \mathrm{~cm}^{-1}$. For each spectrum 64 runs were collected and averaged. Raman spectra of unmodified MWCNT, SAHA modified MWCNT and epoxy/MWCNT/ SAHA composite samples were recorded using a Renishaw 2000, UK system with an Argon ion laser exciting wavelength of $514 \mathrm{~nm}$ over a scanning range of $500-2000 \mathrm{~cm}^{-1}$.

\subsubsection{Thermal properties}

Thermal behavior of neat epoxy and epoxy/ MWCNT composites was studied with DSC (TA instruments Q100 series, USA). About 6-10 mg of sample was placed in an aluminium pan and heated from -80 to $100^{\circ} \mathrm{C}$ with a heating rate of $5^{\circ} \mathrm{C} \cdot \mathrm{min}^{-1}$ and cooled to room temperature. The reference was an empty aluminium pan. Thermogravimetric analysis (TGA) of neat epoxy and the epoxy/MWCNT composite samples were carried out on a thermogravimetric analyzer, TA Instrument (TGA Q500, USA). $6-8 \mathrm{mg}$ of sample was heated from room temperature to $800^{\circ} \mathrm{C}$ at a heating rate of $20^{\circ} \mathrm{C} \cdot \mathrm{min}^{-1}$ under nitrogen atmospheres.

\subsubsection{Dynamic mechanical analysis}

Dynamic mechanical analysis (DMA) of the neat epoxy and epoxy/MWCNT composite samples was carried out using a dynamic mechanical thermal analyzer (MK IV, Rheometric Scientific, USA). The test specimen was cooled to $-80^{\circ} \mathrm{C}$, allowed to stabilize and then heated at a rate of $3^{\circ} \mathrm{C} / \mathrm{min}$ to $100^{\circ} \mathrm{C}$. Liquid nitrogen was used for sub ambient region. Dynamic modulus and loss modulus were obtained by a dual cantilever mode for the sample of size $30 \times 10 \times 2 \mathrm{~mm}^{3}$ using a fixed frequency of $1 \mathrm{~Hz}$. 


\section{Results and discussion}

\subsection{Reaction of modified MWCNT with the epoxy resin}

A good dispersion of MWCNT and interfacial adhesion with the polymer matrix are absolutely necessary to achieve desirable properties of composites. In the absence of sufficient interfacial adhesion between the nanotubes and the polymer, the tubes will be simply pulled-out and will not contribute towards the enhancement of mechanical properties of the composites. We used SAHA to resolve the problem of the good dispersion and interfacial adhesion. SAHA can interact with $\pi$ electron clouds of MWCNT (via cation- $\pi$ interaction) which improves dispersion of MWCNT and also it can form chemical bonding with the epoxy resin. In this way, the nanotubes become an integral part of cross linking through chemical bonding between SAHA and epoxy resin. This provides an effective load transfer from epoxy matrices to nanotubes for the enhancement of mechanical properties. The cation- $\pi$ interaction and chemical modification of MWCNT will be discussed subsequently in spectroscopic analysis section. Schematic representation of the cation- $\pi$ interaction between SAHA with MWCNT, chemical bonding of amino groups of SAHA with epoxy resin and formation of epoxy network is shown in Figure 2.

\subsection{Tensile properties of composites}

Table 1 shows the tensile properties of epoxy/ MWCNT $(0.5 \mathrm{wt} \%) /$ SAHA composites, made using two solvents namely acetone and tetrahydrofuran separately. For comparison the composites with $0.5 \mathrm{wt} \%$ SAHA modified MWCNT was also made without using solvent (Table 1). The MWCNT to SAHA ratio was maintained as $1: 1(\mathrm{w} / \mathrm{w})$. It was observed that the epoxy/MWCNT $(0.5 \mathrm{wt} \%) / \mathrm{SAHA}$ composite made using solvent is much more effective in improvement of tensile properties compared to the composite made without using solvent. This can be attributed to the fact that solvent interacts

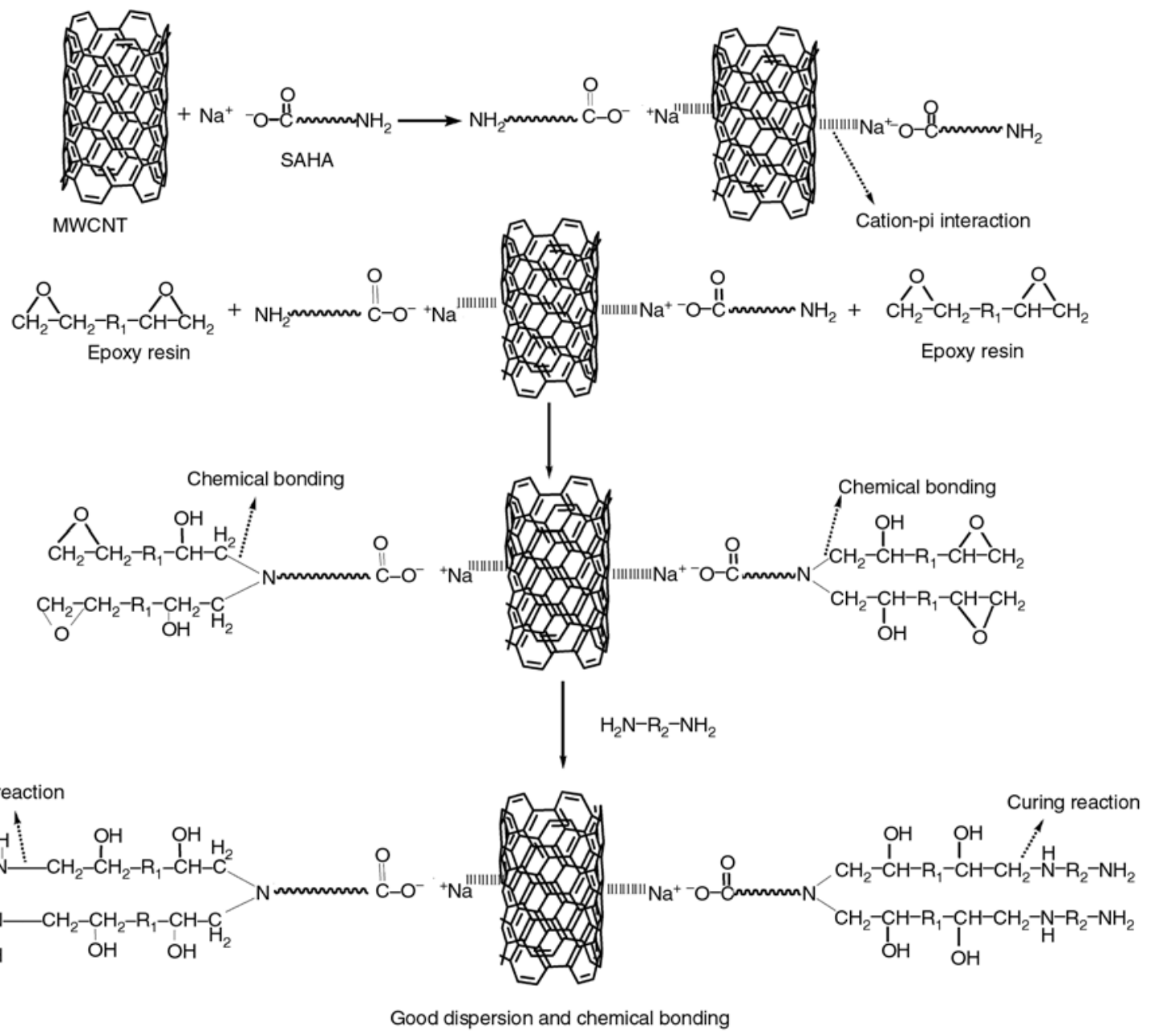

Figure 2. Representation of cation- $\pi$ interaction (cation of the modifier with $\pi$ electron clouds of MWCNT) between the modifier (SAHA) with MWCNT and H-bonding of carboxylic acid of SAHA with epoxy 
Table 1. Tensile properties of epoxy/MWCNT $(0.5 \mathrm{wt} \%) / \mathrm{SAHA}$ composites prepared by using solvent (THF and acetone) and without using solvent

\begin{tabular}{|l|c|c|c|}
\hline \multicolumn{1}{|c|}{ Samples } & $\begin{array}{c}\text { Tensile strength } \\
{[\mathbf{M P a}]}\end{array}$ & $\begin{array}{c}\text { Tensile modulus } \\
{[\mathbf{M P a}]}\end{array}$ & $\begin{array}{c}\text { Elongation at breaks } \\
{[\%]}\end{array}$ \\
\hline Neat epoxy & $0.61 \pm 0.02$ & $0.61 \pm 0.03$ & $121 \pm 7$ \\
\hline Epoxy/MWCNT(0.5 wt\%)/SAHA $(1: 1)$ without solvent & $0.81 \pm 0.03$ & $0.84 \pm 0.05$ & $117 \pm 4$ \\
\hline Epoxy/MWCNT(0.5 wt\%)/SAHA $(1: 1)$ in THF & $0.94 \pm 0.04$ & $1.52 \pm 0.08$ & $77 \pm 3$ \\
\hline Epoxy/MWCNT(0.5 wt\%)/SAHA $(1: 1)$ in acetone & $0.84 \pm 0.03$ & $1.11 \pm 0.05$ & $85 \pm 5$ \\
\hline
\end{tabular}

Table 2. Tensile properties of epoxy/MWCNT $(0.5 \mathrm{wt} \%) / \mathrm{SAHA}$ having different ratio (w/w) of MWCNT to SAHA

\begin{tabular}{|l|c|c|c|}
\hline \multicolumn{1}{|c|}{ Samples } & $\begin{array}{c}\text { Tensile strength } \\
{[\mathrm{MPa}]}\end{array}$ & $\begin{array}{c}\text { Tensile modulus } \\
{[\mathrm{MPa}]}\end{array}$ & $\begin{array}{c}\text { Elongation at breaks } \\
{[\%]}\end{array}$ \\
\hline Neat epoxy $(100: 0: 0)$ & $0.61 \pm 0.02$ & $0.61 \pm 0.03$ & $121 \pm 7$ \\
\hline Epoxy/MWCNT(0.5 wt\%) (100:1:0) & $0.72 \pm 0.03$ & $0.87 \pm 0.02$ & $94 \pm 4$ \\
\hline Epoxy/MWCNT(0.5 wt\%)/SAHA (100:1:0.5) & $0.93 \pm 0.02$ & $1.38 \pm 0.08$ & $73 \pm 3$ \\
\hline Epoxy/MWCNT(0.5 wt\%)/SAHA (100:1:1) & $0.94 \pm 0.04$ & $1.52 \pm 0.06$ & $77 \pm 2$ \\
\hline Epoxy/MWCNT(0.5 wt\%)/SAHA (100:1:1.5) & $1.03 \pm 0.04$ & $1.65 \pm 0.05$ & $75 \pm 4$ \\
\hline Epoxy/MWCNT(0.5 wt\%)/SAHA (100:1:2) & $0.79 \pm 0.03$ & $1.33 \pm 0.04$ & $69 \pm 4$ \\
\hline
\end{tabular}

strongly with the nanotubes and establishes a stable suspension by breaking the agglomeration of MWCNT. Further, we compared the tensile properties of epoxy/MWCNT $(0.5 \mathrm{wt} \%) / \mathrm{SAHA}$ composites prepared by using THF and acetone. The epoxy/ MWCNT $(0.5 \mathrm{wt} \%) / \mathrm{SAHA}$ composite prepared by using tetrahydrofuran showed better performance. This explained that the nature of the solvent is also an important factor to improve the performance of MWCNT in the epoxy matrix. The amine groups of SAHA provides good compatibility with THF compared to the acetone, this leads to debundling of MWCNT and stable suspension of MWCNT. About 54 and $150 \%$ improvement in tensile strength and tensile modulus was obtained for composite prepared using THF. In this case, only $20 \mathrm{wt} \%$ of solvent was used (low molecular weight) for composites preparation, which is much less compared to that used for thermoplastics composite $(>90 \%)$. From the above results, THF was used as a solvent for further synthesis and characterization of epoxy/ MWCNT composites.

The tensile properties of epoxy/MWCNT $(0.5 \mathrm{wt} \%) /$ SAHA composites were made with different MWCNT to SAHA ratio is presented in Table 2. The ratios of MWCNT to SAHA were maintained as 1:0.5, 1:1, 1:1.5, and 1:2(w/w). Among all the composites, the composites prepared by using $1: 1.5$ MWCNT to SAHA ratio showed the best improvement in the tensile strength and tensile modulus (Table 2). It exhibited around 68 and 170\% improvement in the tensile strength and tensile modulus, respectively. This indicates that the addition of optimum concentration (1:1.5) of SAHA and MWCNT resulted in a significant improvement in tensile properties of the composites. This improvement in the tensile property is a combined effect of improved dispersion of MWCNT in the epoxy resin and chemical bonding between the SAHA and the epoxy resin. The good dispersion of MWCNT can be explained in terms of cation- $\pi$ interaction between cation of SAHA and $\pi$ electron of MWCNT. This type of interaction reduces the Van der Waals interaction present within the nanotubes and promotes their debundling. Beyond the optimum concentration of modifier (1:1.5), it does not contribute towards improvement in dispersion and interfacial adhesion, but interfere in curing reaction because of the presence of free amine group. This increases the stoichiometric imbalance in the epoxy/reaction, resulting in deterioration in properties. Similar observation was reported in literature [18]. Hence, 1:1.5 MWCNT to SAHA ratio (referred as SAHA modified MWCNT) was considered as an optimum one and the same was used further for preparation of varying concentration of epoxy/MWCNT composites.

A series of epoxy/MWCNT composites were made using varying concentration of SAHA modified MWCNT and their tensile properties were evaluated. The representative stress-strain curve of neat epoxy, epoxy/MWCNT(0.5 wt\%), and epoxy/ MWCNT $(0.5 \mathrm{wt} \%) / \mathrm{SAHA}$ composites are presented in Figure 3 and the tensile properties are 
Table 3. Tensile properties of epoxy/MWCNT/SAHA (1:1.5) composite having varying concentration [wt $\%$ ] of MWCNT

\begin{tabular}{|c|c|c|c|}
\hline $\begin{array}{c}\text { Samples } \\
\text { (wt\% SAHA modified MWCNT) }\end{array}$ & $\begin{array}{c}\text { Tensile strength } \\
{[\mathbf{M P a}]}\end{array}$ & $\begin{array}{c}\text { Tensile modulus } \\
{[\mathbf{M P a}]}\end{array}$ & $\begin{array}{c}\text { Elongation at breaks } \\
{[\%]}\end{array}$ \\
\hline 0 & $0.61 \pm 0.02$ & $0.61 \pm 0.03$ & $121 \pm 7$ \\
\hline 0.1 & $0.66 \pm 0.02$ & $0.98 \pm 0.03$ & $102 \pm 6$ \\
\hline 0.25 & $0.74 \pm 0.04$ & $1.00 \pm 0.04$ & $90 \pm 3$ \\
\hline 0.5 & $1.03 \pm 0.04$ & $1.65 \pm 0.05$ & $64 \pm 4$ \\
\hline 0.75 & $1.09 \pm 0.02$ & $1.85 \pm 0.07$ & $63 \pm 3$ \\
\hline 1 & $1.16 \pm 0.05$ & $2.22 \pm 0.05$ & $58 \pm 5$ \\
\hline 1.5 & $0.96 \pm 0.04$ & $1.42 \pm 0.06$ & $50 \pm 2$ \\
\hline
\end{tabular}

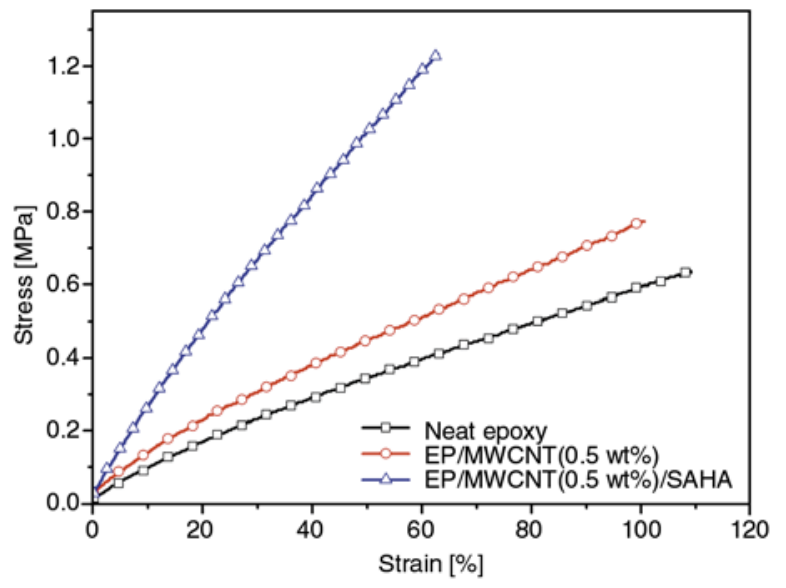

Figure 3. Stress-strain curve of neat epoxy, EP/MWCNT $(0.5 \mathrm{wt} \%)$ and EP/MWCNT(0.5 wt $\%) / \mathrm{SAHA}$

summarized in Table 3. The \% elongation at break was found to decrease significantly due to the incorporation of MWCNT into the epoxy matrix (Figure 3). The increased tensile modulus is more prominent in case of modified MWCNT compared to unmodified MWCNT composites. It can be seen

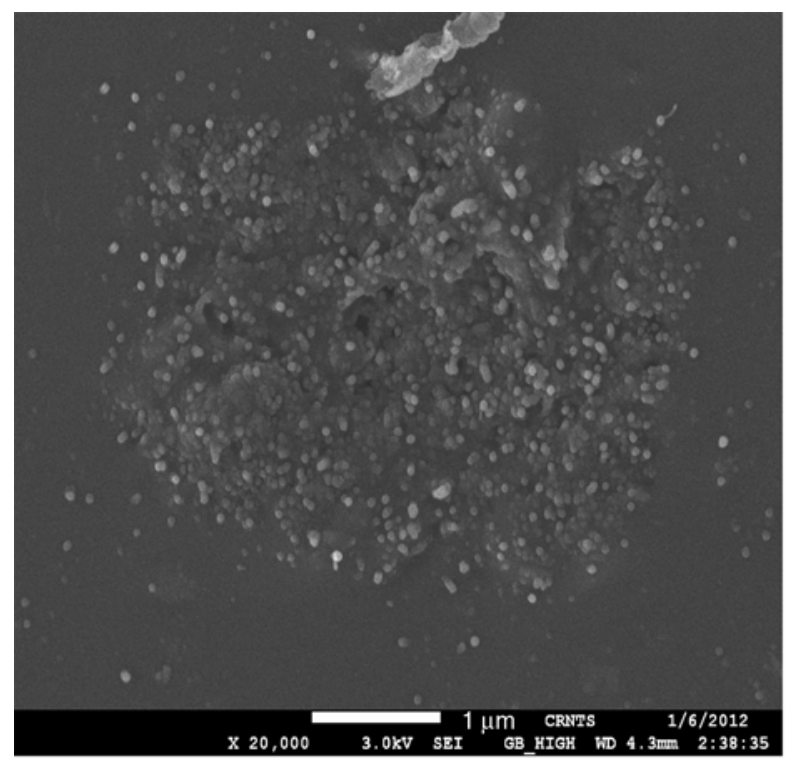

a) that from Table 3, the tensile properties of epoxy/ MWCNT composite increased with increasing concentration of MWCNT up to $1 \mathrm{wt} \%$ and decreased thereafter. Addition of $1 \mathrm{wt} \%$ SAHA modified MWCNT into epoxy matrix showed around 90, and $264 \%$ improvement in tensile strength and tensile modulus, respectively. This improvement can be attributed to the good dispersion of MWCNT into the epoxy matrix. The decreased tensile properties of composites beyond $1 \mathrm{wt} \%$ due to agglomerated MWCNT, as evidenced by SEM and TEM which will be discussed in subsequent section.

\subsection{Microscopic analysis}

The epoxy composite prepared using unmodified MWCNT and SAHA modified MWCNT were characterized by SEM to study the dispersion state of MWCNT in the epoxy matrix. The composite samples were cryogenically fractured and the fracture surface was subjected to SEM analysis. Figure 4

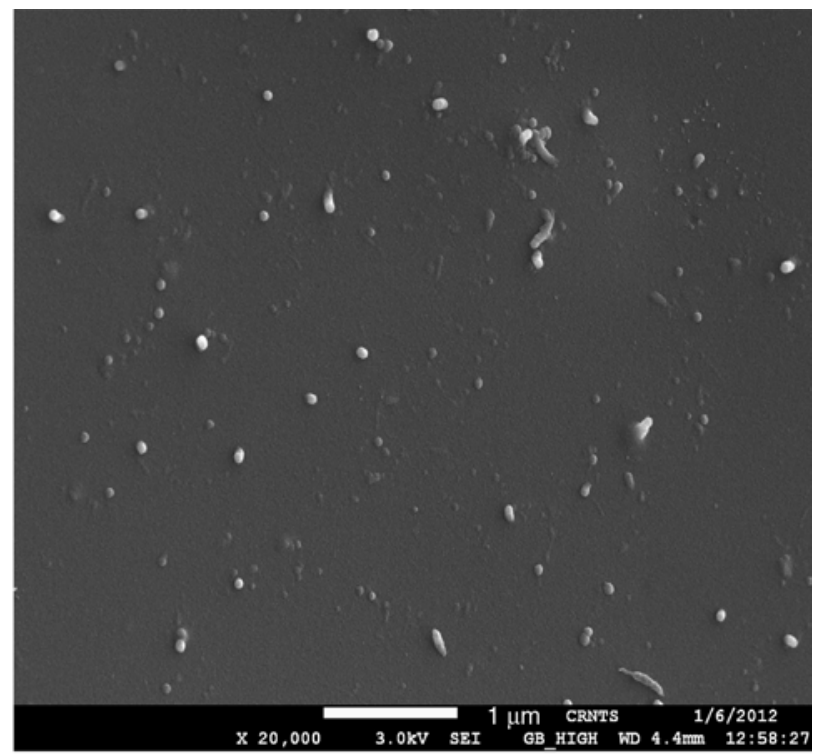

b)

Figure 4. SEM photographs of epoxy/MWCNT composites with (0.5 wt\%) (a), unmodified MWCNT and SAHA-modified MWCNT (b) 
shows the photographs of epoxy/MWCNT( $0.5 \mathrm{wt} \%)$ and epoxy/MWCNT( $0.5 \mathrm{wt} \%) / \mathrm{SAHA}$ composite samples. The agglomerated nanotubes can be seen on the fractured surface of the epoxy/MWCNT $(0.5 \mathrm{wt} \%)$ composite (Figure $4 \mathrm{a})$. The broken ends of unmodified MWCNT simply pulled out from the matrix indicating poor dispersion and absence of interfacial adhesion. On the other hand, the epoxy/ MWCNT/SAHA composite showed well dispersed nanotubes throughout the epoxy matrix (Figure 4b). This implies that the modification of MWCNT by SAHA provides not only good dispersion but also good interfacial adhesion.

In order to substantiate the dispersion of MWCNT, the epoxy/MWCNT composite samples were further characterized by TEM. TEM photographs of epoxy/MWCNT, epoxy/MWCNT(0.5 wt $\%$ )/SAHA, epoxy/MWCNT(1 wt $\%) / S A H A$ and epoxy/MWCNT $(1.5 \mathrm{wt} \%) /$ SAHA composites are shown in Figure 5. Epoxy/MWCNT(0.5 wt $\%)$ clearly demon-

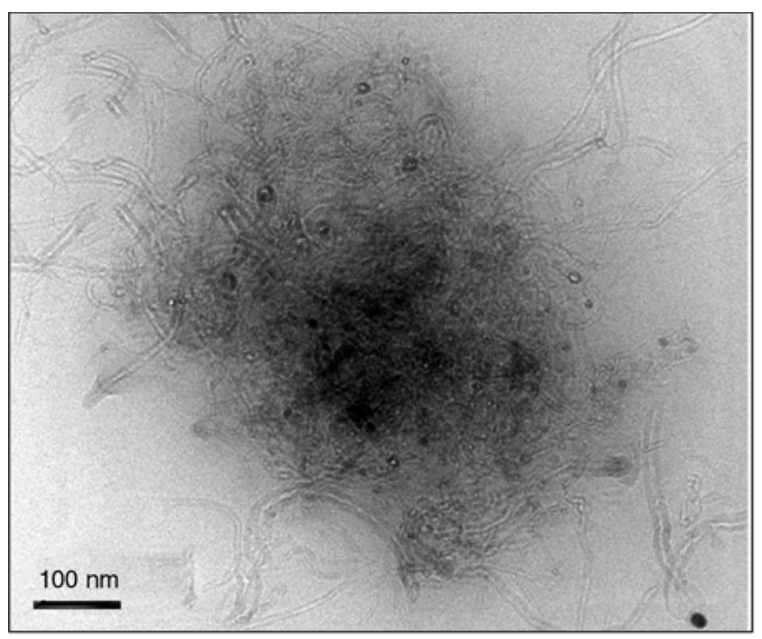

a)

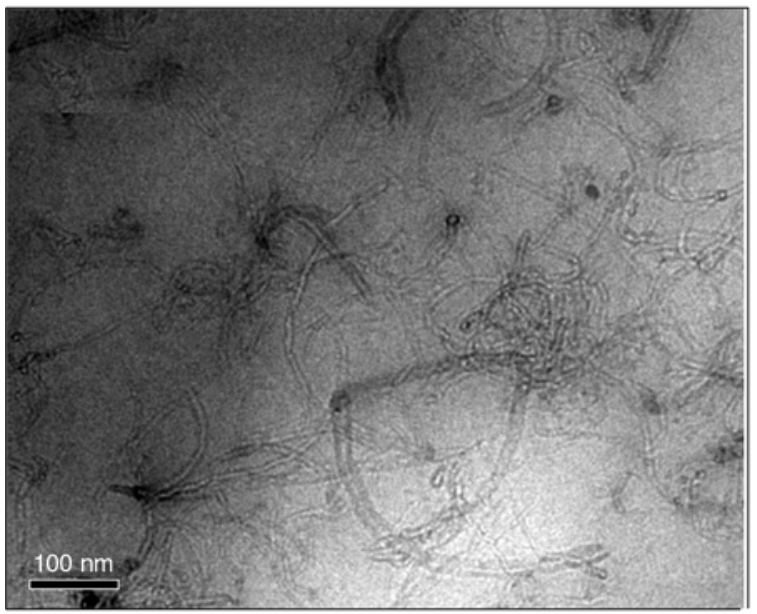

c) strate poor dispersion of MWCNT and high degree of agglomeration (Figure 5a). The well separated nanotubes can be seen for the epoxy/MWCNT $(0.5 \mathrm{wt} \%) / \mathrm{SAHA}$ and epoxy/MWCNT( $1 \mathrm{wt} \%)$ /SAHA composites (Figure 5b and 5c). This can be explained by considering fact that the debundling of nanotubes due to the cation- $\pi$ interaction and chemical bonding as described in Figure 2. TEM photograph of epoxy/MWCNT(1.5 wt\%) /SAHA composite indicates that at higher concentration of MWCNT it is difficult to prevent the agglomeration. This explains why tensile property decreases beyond $1 \mathrm{wt} \%$ MWCNT as discussed earlier.

\subsection{Spectroscopic analysis}

Raman spectrum for MWCNT, SAHA modified MWCNT and epoxy/MWCNT( $1 \mathrm{wt} \%$ )/SAHA composite is shown in Figure 6. The spectrum of unmodified MWCNT shows two characteristics peak of $G$ and $D$ band. The $D$ band of MWCNT arises due to

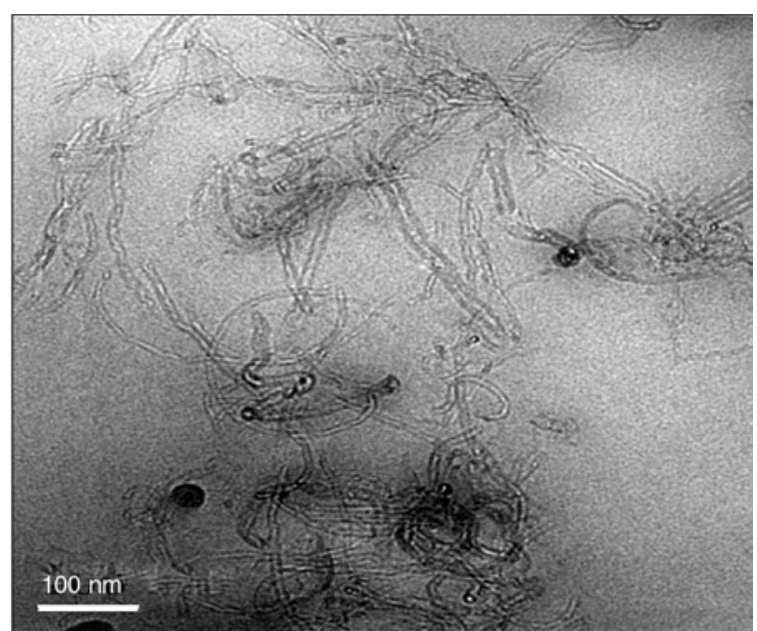

b)

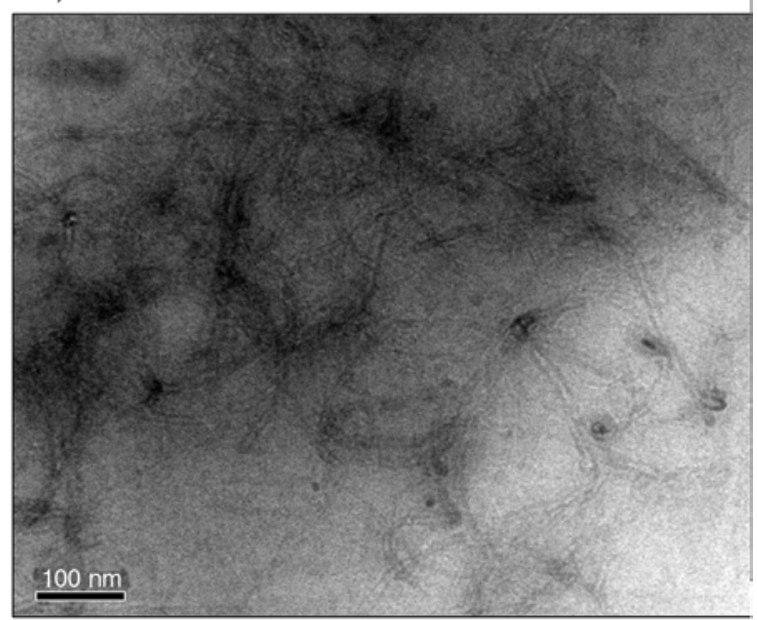

d)

Figure 5. TEM photographs of epoxy /MWCNT composites (a) unmodified-MWCNT(0.5 wt $\%$ ); (b) (0.5 wt $\%$ ) SAHAmodified MWCNT, (c) (1 wt \%) SAHA-modified MWCNT and (d) (1.5 wt \%) SAHA modified MWCNT 


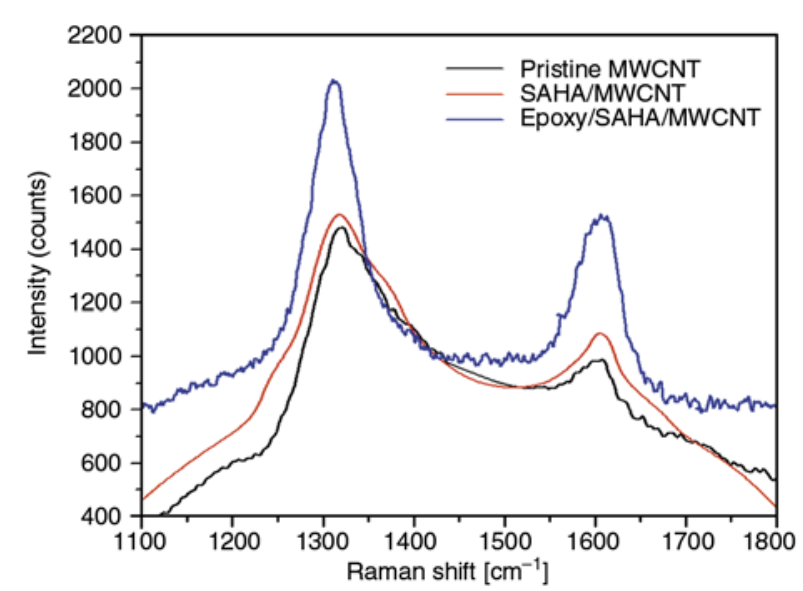

Figure 6. Raman spectra for pristine MWCNT, SAHA modified MWCNT and epoxy/SAHA/MWCNT composite

the disorder graphitic structure, and corresponding $G$ band is due to tangential stretching of carbon carbon bond. There is no shift in the peak position of $G$ band and $D$ band of MWCNT, when MWCNT mixed with SAHA. This observation confirms that the modification of MWCNT with SAHA did not generate any defect on to the surface of MWCNT. It was also observed that upon modification the peak intensity of $G$ and $D$ band shifted towards higher intensity. Epoxy/MWCNT/SAHA composite also shows the higher peak intensity of $G$ and $D$ band of MWCNT compared to the unmodified MWCNT and SAHA modified MWCNT. The higher peak intensity of MWCNT after modification can be explained by considering the cation- $\pi$ interaction (between SAHA and MWCNT) which is responsible for reduction of Van der Waals force within the MWCNT resulting in their good dispersion in polymer matrix [18, 27].

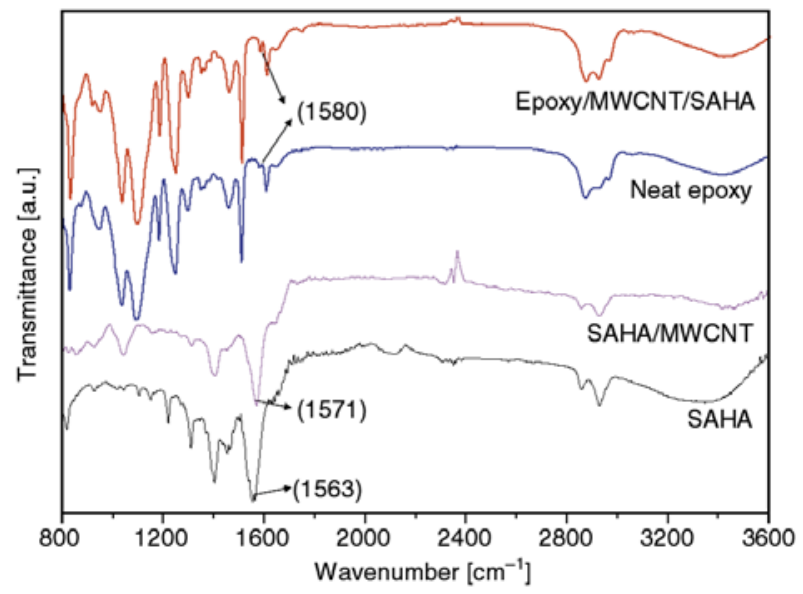

Figure 7. FTIR spectra for SAHA, SAHA modified MWCNT, neat epoxy and epoxy/MWCNT(1 wt $\%) / \mathrm{SAHA}$ composite
The FTIR spectra of SAHA, SAHA modified MWCNT, neat epoxy and epoxy/MWCNT(1 wt \%)/ SAHA composite samples are presented in Figure 7. The SAHA shows a characteristic peaks at $1563 \mathrm{~cm}^{-1}$ corresponds to $\mathrm{C}=\mathrm{O}$ stretching of carboxylate group. The $\mathrm{C}=\mathrm{O}$ stretching peak of carboxylate group is shifted from 1563 to $1571 \mathrm{~cm}^{-1}$ for SAHA modified MWCNT. This can be explained by considering the cation- $\pi$ interaction between the SAHA and MWCNT. The cation of SAHA interact with $\pi$ electron cloud of MWCNT and reduces the effectiveness of dislocation of negative charge on oxygen atom of the carboxylate ion by reducing the electron density on the charged oxygen atom; resulting in higher wave number of the carboxylate group. The epoxy/MWCNT(0.5 wt\%)/SAHA composite also exhibits a shift of the peak of corresponding $\mathrm{C}=\mathrm{O}$ group of the carboxylate ion from 1563 to $1580 \mathrm{~cm}^{-1}$. It can be noted that the less intense peak at $1580 \mathrm{~cm}^{-1}$ appear also in case of the neat epoxy which corresponds to $\mathrm{Ar}-\mathrm{C}=\mathrm{C}-\mathrm{H}$ stretching. The same peak

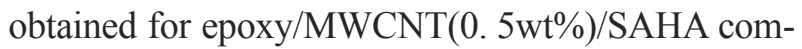
posite has stronger intensity. This can be attributed to overlapping of carboxylate ion peak and $\mathrm{Ar}-\mathrm{C}=\mathrm{C}-\mathrm{H}$ group stretching in this region.

\subsection{Thermal analysis}

Table 4 shows glass transition temperature of the neat epoxy, epoxy/MWCNT and epoxy/MWCNT/ SAHA composites measured by DSC and DMA. It was observed that the $T_{\mathrm{g}}$ of all composite sample shifted towards the lower temperature compared to $T_{\mathrm{g}}$ of the neat epoxy which will be discussed in DMA analysis in subsequent section. In order to study the effect of addition of the modified MWCNT on the thermal stability of composites, the neat epoxy and the epoxy/MWCNT/SAHA composite samples were subjected to TGA and results are shown in Figure 8. It can be seen that, the epoxy/MWCNT/

Table 4. Glass transition temperature of neat epoxy and epoxy/MWCNT composites measured by DSC and DMA

\begin{tabular}{|l|c|c|}
\hline \multicolumn{1}{|c|}{ Sample } & $\begin{array}{c}\text { DSC } \\
\mathbf{T}_{\mathbf{g}} \\
{\left[{ }^{\circ} \mathbf{C}\right]}\end{array}$ & $\begin{array}{c}\text { DMA } \\
\mathbf{T}_{\mathbf{g}} \\
{\left[{ }^{\circ} \mathbf{C}\right]}\end{array}$ \\
\hline Neat epoxy & -8 & 5 \\
\hline Epoxy/MWCNT $(0.5 \mathrm{wt} \%)$ & -7 & 6 \\
\hline Epoxy/MWCNT $(0.5 \mathrm{wt} \%) / \mathrm{SAHA}$ & -10 & 3 \\
\hline Epoxy/MWCNT $(0.75 \mathrm{wt} \%) / \mathrm{SAHA}$ & -10 & 2 \\
\hline Epoxy/MWCNT $(1 \mathrm{wt} \%) / \mathrm{SAHA}$ & -13 & 1 \\
\hline Epoxy/MWCNT $(1.5 \mathrm{wt} \%) / \mathrm{SAHA}$ & -11 & 4 \\
\hline
\end{tabular}




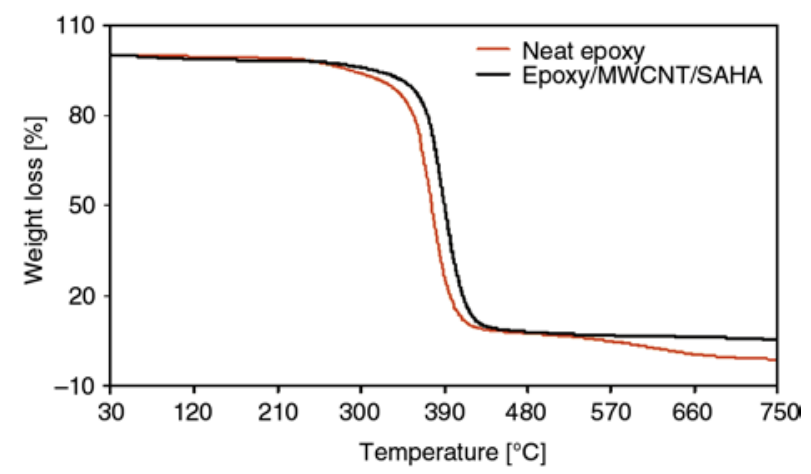

Figure 8. TGA plots of neat epoxy and epoxy/MWCNT/ SAHA composite

SAHA composite exhibited higher thermal stability compared to the neat epoxy. This improvement in the thermal stability of the epoxy/MWCNT composite is due to well dispersed nanotubes and strong interfacial adhesion between nanotubes and epoxy matrix. The strong interfacial adhesion of MWCNT with epoxy matrix reduces the mobility of the epoxy matrix around the nanotubes and thereby enhances the thermal stability [28].

\subsection{Dynamic mechanical analysis}

The storage modulii as a function of temperature for the neat epoxy, epoxy/MWCNT(0.5 wt\%), epoxy/ MWCNT $(0.5 \mathrm{wt} \%) / \mathrm{SAHA}$, epoxy/MWCNT(1 wt $\%)$ and epoxy/MWCNT(1.5 wt $\%$ SAHA) composite are shown in Figure 9. The epoxy/MWCNT $(0.5 \mathrm{wt} \%)$ composite exhibits the moderate improvement in the storage modulus compared to the neat epoxy. This can be explained by the inert surface of unmodified MWCNT cannot make any kinds of interaction with epoxy matrix (Figure 4 and Figure 5). On the other hand, epoxy/MWCNT(0.5 wt $\%) /$ SAHA and epoxy/MWCNT(1 wt $\%) / S A H A$ composites show

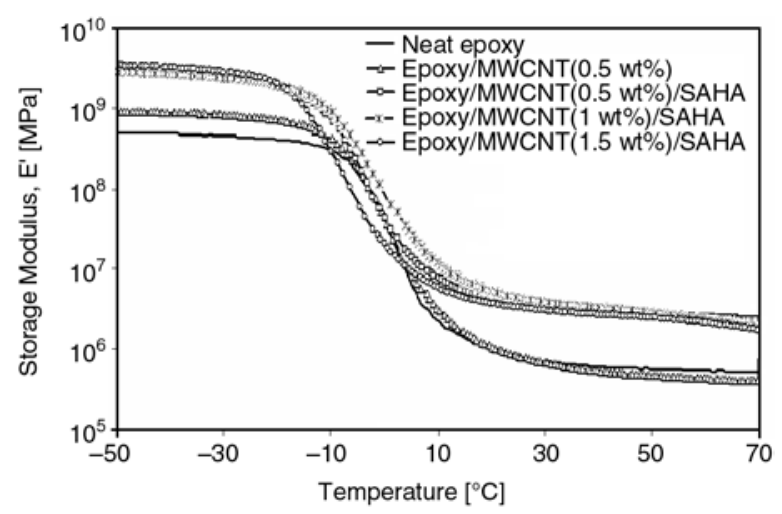

Figure 9. Storage modulus vs. temperature plots for neat epoxy, epoxy/MWCNT( $0.5 \mathrm{wt} \%)$, epoxy/MWCNT $(0.5 \mathrm{wt} \%) / \mathrm{SAHA}$, epoxy/MWCNT(1 wt $\%) / \mathrm{SAHA}$ and epoxy/MWCNT(1.5 wt $\%) / \mathrm{SAHA}$ significant improvement in the storage modulus. This is due to the reinforcing effect of MWCNT. The reinforcing effect is a result of good dispersion and strong interfacial adhesion (chemical bonding) between nanotubes and epoxy matrix. The good dispersion of MWCNT is believed to originate from the cation- $\pi$ interaction and interfacial adhesion due to the chemical bonding of SAHA and epoxy matrix (Figure 2). The lowering of storage modulus in case of epoxy/MWCNT(1.5 wt $\%)$ /SAHA compared to

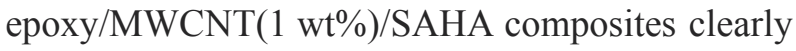
indicated that reinforcing effect of MWCNT decreased when concentration of MWCNT goes beyond $1 \mathrm{wt} \%$. This supports the tensile, SEM and TEM results as discussed earlier.

The loss tangent vs. temperature plot of neat epoxy, epoxy/MWCNT(0.5 wt \%), epoxy/MWCNT(0.5 wt \%)/ SAHA, epoxy/MWCNT(1 wt\%)/SAHA and epoxy/ MWCNT(1.5 wt \%)/SAHA are shown in Figure 10. All the composites show reduction in the $\tan \delta$ peak height due to the addition of MWCNT. This indicates that the restricted mobility of polymer chain which increases rigidity and stiffness of the composites. The moderate reduction in the $\tan \delta$ peak height in case of epoxy/MWCNT composite indicates the absence of any interaction (cation- $\pi$ and chemical bonding) between MWCNT with epoxy matrix. On the other hand, a significant decrease in the $\tan \delta$ peak height was observed due to the addition SAHA modified MWCNT (Figure 10). This is because SAHA modified MWCNTs (well dispersed) restrict the segmental motion of the epoxy around the nanotubes surface. The glass transition temperature of neat epoxy and all the composite samples are listed in Table 4. It can be noted that the glass transition temperature $\left(T_{\mathrm{g}}\right)$ tends to decrease due to

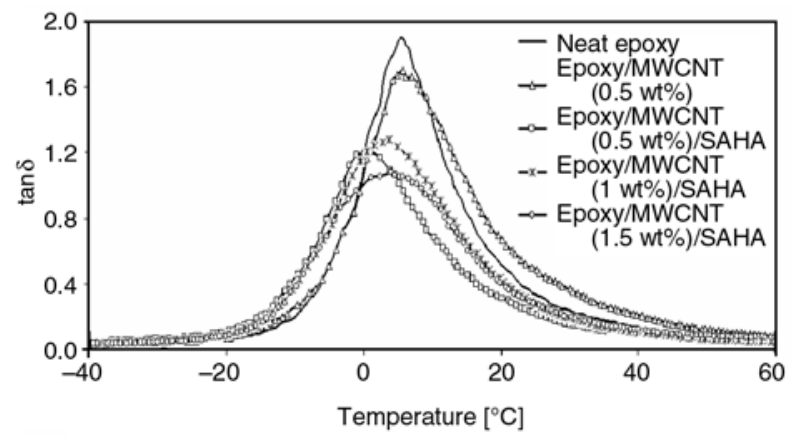

Figure 10. Loss tangent vs. temperature plots for neat epoxy, epoxy/MWCNT(0.5 wt \%), epoxy/MWCNT $(0.5 \mathrm{wt} \%) / \mathrm{SAHA}, \quad$ epoxy/MWCNT( $1 \mathrm{wt} \%) /$ SAHA and epoxy/MWCNT(1.5 wt $\%) /$ SAHA 
the addition of SAHA modified MWCNT compared to neat epoxy. The lowering of $T_{\mathrm{g}}$ is due to the reaction of amine group of SAHA with epoxy resin resulting non-stoichiometric balance between epoxy resins and curing agent, and thus leading to the inhibition of crosslinking reaction to a certain extent between them [29].

\section{Conclusions}

A detailed study on effect of SAHA modified MWCNT on tensile properties; thermomechanical properties and dispersion of MWCNT have been conducted. The dispersion of MWCNT in the epoxy matrix is significantly improved due to the use of SAHA as a modifier. The addition of optimum concentration of modified MWCNT( $1 \mathrm{wt} \%$ ) resulted in around 90 and $264 \%$ improvement in the tensile strength and tensile modulus, respectively. The good dispersion of MWCNT is a result of cation- $\pi$ interaction between SAHA and MWCNT. The present approach does not disturb the $\pi$ electron cloud of CNT as opposed to chemical functionalization.

\section{References}

[1] Iijima S.: Helical microtubules of graphitic carbon. Nature, 354, 56-84 (1991).

DOI: $10.1038 / 354056 a 0$

[2] Schaefer W. D., Justice S. R.: How nano are nanocomposites? Macromolecules, 40, 8501-8517 (2007). DOI: $10.1021 / \mathrm{ma} 070356 \mathrm{w}$

[3] Treacy M. M. J., Ebbesen T. W., Gibson J. M.: Exceptionally high Young's modulus observed for individual carbon nanotubes. Nature, 381, 678-680 (1996). DOI: $10.1038 / 381678 \mathrm{a} 0$

[4] Gojny F. H., Nastalczyk J., Roslaniec Z., Schulte K.: Surface modified multi-walled carbon nanotubes in CNT/epoxy-composites. Chemical Physics Letters, 370, 820-824 (2003).

DOI: $10.1016 / \mathrm{S} 0009-2614(03) 00187-8$

[5] Haggenmueller R., Gommans H. H., Rinzler A. G., Fischer J. E., Winey K. I.: Aligned single-wall carbon nanotubes in composites by melt processing methods. Chemical Physics Letters, 330, 219-225 (2000). DOI: 10.1016/S0009-2614(00)01013-7

[6] Dalton A. B., Collins S., Muñoz E., Razal J. M., Ebron V. H., Ferraris J. P., Coleman J. N., Kim B. G., Baughman R. H.: Super-tough carbon-nanotube fibres. Nature, 423, 703 (2003).

DOI: $10.1038 / 423703 \mathrm{a}$

[7] Kumar S., Doshi H., Srinivasarao M., Park J. O., Schiraldi D. A.: Fibers from polypropylene/nano carbon fiber composites. Polymer, 43, 1701-1703 (2002). DOI: $10.1016 / \mathrm{S} 0032-3861(01) 00744-3$
[8] Lozano K., Yang S., Jones R. E.: Nanofiber toughened polyethylene composites. Carbon, 42, 2329-2331 (2004).

DOI: $10.1016 /$ j.carbon.2004.03.021

[9] Hill D. E., Lin Y., Rao A. M., Allard L. F., Sun Y-P.: Functionalization of carbon nanotubes with polystyrene. Macromolecules, 35, 9466-9471 (2002).

DOI: $10.1021 / \mathrm{ma} 020855 \mathrm{r}$

[10] Hong C-Y., You Y-Z., Pan C-Y.: Functionalized multiwalled carbon nanotubes with poly( $N$-(2-hydroxypropyl)methacrylamide) by RAFT polymerization. Journal of Polymer Science Part A: Polymer Chemistry, 44, 2419-2427 (2006).

DOI: $10.1002 /$ pola.21341

[11] Kong H., Gao C., Yan D.: Functionalization of multiwalled carbon nanotubes by atom transfer radical polymerization and defunctionalization of the products. Macromolecules, 37, 4022-4030 (2004). DOI: $10.1021 / \mathrm{ma} 049694 \mathrm{c}$

[12] Du J-H., Bai J., Cheng H-M.: The present status and key problems of carbon nanotube based polymer composites. Express Polymer Letters, 1, 253-273 (2007). DOI: $10.3144 /$ expresspolymlett.2007.39

[13] Zhao B., Hu H., Yu A., Perea D., Haddon R. C.: Synthesis and characterization of water soluble singlewalled carbon nanotube graft copolymers. Journal of the American Chemical Society, 127, 8197-8203 (2005). DOI: $10.1021 / \mathrm{ja} 042924 \mathrm{i}$

[14] Qu L., Lin Y., Hill D. E., Zhou B., Wang W., Sun X., Kitaygorodskiy A., Suarez M., Connell J. W., Allard L. F., Sun Y-P.: Polyimide-functionalized carbon nanotubes: Synthesis and dispersion in nanocomposite films. Macromolecules, 37, 6055-6060 (2004). DOI: $\underline{10.1021 / \mathrm{ma} 0491006}$

[15] Fukushima T., Kosaka A., Ishimura Y., Yamamoto T., Takigawa T., Ishii N., Aida T.: Molecular ordering of organic molten salts triggered by single-walled carbon nanotubes. Science, 300, 2072-2074 (2003).

DOI: $10.1126 /$ science. 1082289

[16] Kodgire P. V., Bhattacharyya A. R., Bose S., Gupta N., Kulkarni A. R., Misra A.: Control of multiwall carbon nanotubes dispersion in polyamide 6 matrix: An assessment through electrical conductivity. Chemical Physics Letters, 432, 480-485 (2006). DOI: $10.1016 /$ j.cplett.2006.10.088

[17] Ratna D., Abraham T. N., Siengchin S., Karger-Kocsis J.: Novel method for dispersion of multiwall carbon nanotubes in poly(ethylene oxide) matrix using dicarboxylic acid salts. Journal of Polymer Science Part B: Polymer Physics, 47, 1156-1165 (2009).

DOI: $10.1002 /$ polb. 21713

[18] Jagtap S. B., Kushwaha R. K., Ratna D.: Poly(ethylene oxide)-multiwall carbon nanotube composites: Effect of dicarboxylic acid salt-based modifiers. Journal of Applied Polymer Science, in press (2013). DOI: $10.1002 /$ app.38112 
[19] Sandler J., Shaffer M. S. P., Prasse T., Bauhofer W., Schulte K., Windle A. H.: Development of a dispersion process for carbon nanotubes in an epoxy matrix and the resulting electrical properties. Polymer, 40, 59675971 (1999).

DOI: 10.1016/S0032-3861(99)00166-4

[20] Schadler L. S., Giannaris S. C., Ajayan P. M.: Load transfer in carbon nanotube epoxy composites. Applied Physics Letters, 73, 3842-3844 (1998).

DOI: $10.1063 / 1.122911$

[21] Guadagno L., De Vivo B., Di Bartolomeo A., Lamberti P., Sorrentino A., Tucci V., Vertuccio L., Vittoria V.: Effect of functionalization on the thermo-mechanical and electrical behavior of multi-wall carbon nanotube/ epoxy composites. Carbon, 49, 1919-1930 (2011). DOI: 10.1016/j.carbon.2011.01.017

[22] Tanaka M., Taguchi J., Kato R.: Effects of microstructures on the creep-rupture properties and fracture mechanisms in austenitic heat-resistant steels. Materials Science and Engineering: A, 410-411, 79-84 (2005). DOI: $10.1016 /$ j.msea.2005.08.007

[23] Zhou W., Du Z-J., Liu Y-X., Yang X., Li H-Q., Zhang C.: Functionalization of MWNTs using polyacryloyl chloride and the properties of CNT-epoxy matrix nanocomposites. Composites Science and Technology, 68, 3259-3264 (2008).

DOI: $10.1016 /$ j.compscitech.2008.08.011

[24] Ma P. C., Kim J-K., Tang B. Z.: Effects of silane functionalization on the properties of carbon nanotube/ epoxy nanocomposites. Composites Science and Technology, 67, 2965-2972 (2007).

DOI: $\underline{10.1016 / \text { j.compscitech.2007.05.006 }}$
[25] Yang Z., McElrath K., Bahr J., D’Souza N. A.: Effect of matrix glass transition on reinforcement efficiency of epoxy-matrix composites with single walled carbon nanotubes, multi-walled carbon nanotubes, carbon nanofibers and graphite. Composites Part B: Engineering, 43, 2079-2086 (2012).

DOI: 10.1016/j.compositesb.2012.01.049

[26] Ratna D., Manoj N. R., Chandrasekhar L., Chakraborty B. C.: Novel epoxy compositions for vibration damping applications. Polymers for Advanced Technologies, 15, 583-586 (2004).

DOI: $10.1002 /$ pat.513

[27] Bose S., Bhattacharyya A. R., Khare R. A., Kulkarni A. R., Patro T. U., Sivaraman P.: Tuning the dispersion of multiwall carbon nanotubes in co-continuous polymer blends: A generic approach. Nanotechnology, 19, 335704/1-335704/8 (2008).

DOI: $10.1088 / 0957-4484 / 19 / 33 / 335704$

[28] Cao Y., Feng J., Wu P.: Preparation of organically dispersible graphene nanosheet powders through a lyophilization method and their poly(lactic acid) composites. Carbon, 48, 3834-3839 (2010).

DOI: $10.1016 /$ j.carbon.2010.06.048

[29] Shen J., Huang W., Wu L., Hu Y., Ye M.: The reinforcement role of different amino-functionalized multi-walled carbon nanotubes in epoxy nanocomposites. Composites Science and Technology, 67, 30413050 (2007).

DOI: 10.1016/j.compscitech.2007.04.025 